\title{
Reseña de Gargallo Celentani (2014) Feminismos desde Abya Yala
}

\author{
Ma Aránzazu Robles Santana \\ Universidad de La Laguna
}

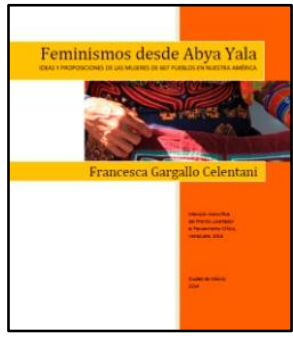

La historiadora de las ideas Francesca Gargallo Celentani tras un extenso, intenso y amplio -geográfica y analíticamente hablandotrabajo de campo (desde tierras mexicanas hasta chilenas), ha compilado para nuestro conocimiento un maravilloso acercamiento a las ideas y proposiciones de las mujeres de 607 pueblos de la llamada América Latina, de Nuestra América ${ }^{1}$, de su América, de Abya Ya$1 a^{2}$.

El trabajo ha sido doble y en una doble dirección - valga la redundancia-, la primera di-

\footnotetext{
${ }^{1}$ Nuestra América nos refiere al Ensayo del mismo nombre que el poeta cubano José Martí escribió en 1891; es un concepto que nos acerca a la diversidad cultural de América, ya que el término "Latino" deja fuera a las poblaciones indígenas. Nuestra América es un concepto no hegemónico y decolonizador que trata de alejarse de la América dominada por la cultura y el poder occidental. ${ }^{2}$ Abya Yala es una expresión del Pueblo Indígena Kuna del Panamá que designa el territorio americano. Esta expresión nos permite reconocer América desde sus raíces indígenas y no desde una perspectiva histórica que nombra e identifica al continente a partir de la colonización europea.
}

\section{Gargallo Celentani, Francesca}

(2014). Feminismos desde Abya Yala. México DF: Corte y Confección. ISBN: 978-9588454597

Versión online rección apunta a un trabajo de conciencia, ya que la autora ha tenido que despojarse de todas sus raíces culturales fundadas en un sistema capitalista y racista, y distanciarse por un lado de los patrones académicos en los que ha sido formada $-y$ del que forma parte-, así como de los privilegios que como ella misma dice,

El sistema racista me ha reservado desde la infancia. Están tan interiorizados y normalizados que no me percato de ellos, y por ende, me abrogo el derecho de no reconocerlos, a menos que alguien me los señale (Gargallo Celentani, 2014, p. 15).

En este sentido y como continúa diciendo:

\begin{abstract}
Debía exponerme a ser aceptada o rechazada, desconocida o considerada una interlocutora válida, a partir de una reflexión sobre mi lugar como mujer blanca en la historia del racismo occidental y la hegemonía que reviste en la construcción y transmisión de saberes (p. 17).
\end{abstract}

La segunda dirección se construye en el camino, en el camino andado, en el trabajo de campo propiamente dicho, en esa búsqueda 
de las distintas expresiones y saberes desde la realidad de ellas, de las mujeres indígenas y solamente desde ellas.

Diversos pueblos originarios de visitados como Totonicapán (Guatemala), Intibucá (Honduras), Bambú (Costa Rica), Kuna Yala (Panamá), Huancavelica (Perú), y muchos más, donde las mujeres, las relaciones de género y sus comportamientos no son homogéneos, lo que da lugar a una complejidad de pensamientos, formas de acción y de lucha divergentes que se plasman en los resultados de la investigación.

El libro que sobrevive se caracteriza por su claridad en los cuestionamientos, por su cabal orden y por su franqueza en las afirmaciones que se manifiestan, las cuales se entroncan (por utilizar el término en uso del Feminismo Comunitario, que la misma autora también añade a su vocabulario) con las palabras textuales de las protagonistas vertidas en las páginas del texto. El diálogo con ellas es por tanto, el método y el producto de la investigación, sin mediaciones, sin críticas.

Y es interesante porque no es la autora la que genera conclusiones fruto del análisis al que se enfrenta, sino que son las mujeres como personas reconocidas con su propia epistemología las que van hilvanando el objeto de la investigación, a saber, la búsqueda de la existencia, o no, de un /varios feminismo(s) indígena(s).

Para acercarse teóricamente a este objetivo, la autora parte de la base del cuestionamiento de los preceptos asimilados en la sociedad de la "modernidad" y busca reconocerlos a través de un pensamiento ajeno a estos patrones de conocimiento. En ese sentido el debate individualismo-comunitarismo queda reflejado en las páginas del libro, donde se perciben las posiciones contrarias al sujeto femenino emancipado, liberal y autónomo que persigue el feminismo occidental, ese feminismo hegemónico que ha sido y es definido desde parámetros eurocéntricos y occidentalizados en pro de una libertad individual que queda muy lejos de la lucha por los derechos que las mujeres indígenas de América Latina buscan en el interior de sus comunidades en un primer término.

El origen del androcentrismo en los pueblos indígenas, así como su expresión, la forma de combatirlo y el resultado que se busca no es similar al de la lucha feminista convencional, "se trata de un pensar el feminismo que arranca de interpretaciones cotidianas de la realidad femenina en las comunidades, en las familias o en el destierro" (p. 113),

El propio feminismo indígena que elabora estrategias comunitarias para el cuidado de las mujeres y la socialización de su trabajo de reproducción de la vida, no podría existir si la comunidad desapareciera e impusiera un sistema individualista de sobrevivencia monetaria asalariada y una familia nuclear centrada en la pareja como núcleo excluyente, asocial, paradójicamente convertido por el capitalismo en la 'base' de la sociedad (Gargallo Celentani, 2014, p. 121).

En este sentido, la descolonización, la despatriarcalización, la opresión sexual y la dominación colonial son aspectos debatidos en el texto y que proporcionan herramientas teóricas para el mejor entendimiento de la particularidad de los ¿feminismos? a los que nos acercamos a través de las páginas de este libro. Feminismos en interrogantes, porque no todas las mujeres indígenas que luchan por acabar con el patriarcado y con el machismo inscrito en sus vidas se declaran o se sienten cómodas bajo el apelativo "feministas"; de esta forma, los modos de combatir la opresión patriarcal se encuentran inscritos en múltiples formas de gestión que no siempre son bienvenidas en el campo epistemológico y metodológico que el feminismo podría abarcar.

La propia historia de las comunidades indígenas y en el particular que nos ocupa de sus mujeres, vincula su reconocimiento como mujeres con derecho a tener derechos desde otras perspectivas que son rescatadas en el texto: se tiene en cuenta la triple dominación que sufren -racial, patriarcal y clasista- enraizándola con cuestionamientos profundos asociados a su idiosincrasia y vida en comunidad, donde la reciprocidad y no la equidad, la equivalencia o la emancipación, son los objetivos de su lucha. Desde estas raíces se teje su propio "feminismo", o su accionar en contra de un sistema machista que les desvaloriza y les excluye.

A través de un extenso debate con mujeres indígenas jóvenes, adultas, desplazadas, urbanas, letradas, analfabetas, académicas, activistas, madres y un largo etcétera en el que se analizan posiciones teóricas hegemónicas, líneas de pensamiento indígenas, procesos de discriminación e inferiorización -véase racis- 
mo y sexismo-, y categorías analíticas como el cuerpo, la comunidad o la naturalización de las opresiones, llegamos a la comprensión del concepto Territorio-Cuerpo (a decir de la Xinka Lorena Cabnal y el Feminismo Comunitario de las altas montañas de Guatemala) de las mujeres indígenas, al conocimiento, reconocimiento y estructuración de su pensamiento en su mayoría desubicado de los posicionamientos teóricos occidentalizados.

Por este motivo, especial atención requieren los llamados Feminismos Comunitarios, a los que se les dedica un capítulo del libro, donde sus integrantes, principalmente las Aymaras bolivianas de Comunidad Mujeres Creando Comunidad, representadas por Julieta Paredes, y las Xinkas de la Asociación de Mujeres Indígenas Xinkas de Santa María de Xalapán Jalapa de Guatemala, representadas por Lorena Cabnal, ven el Feminismo no como una categoría occidental a combatir, sino como una herramienta teórica que les ha dado la posibilidad de pensarse como mujeres capacitadas y estructurar un pensamiento y acción destinado a cuestionar y romper con los patrones patriarcales, heteronormativos y heterosexuales establecidos; no sólo los heredados del colonialismo, sino también los que perduran desde tiempos anteriores a la colonia, destapando así un patriarcado ancestral. Ambos patriarcados dan lugar a lo que han denominado el Entronque Patriarcal como la consecuencia de estos dos sistemas de poder de dominación sobre el cuerpo de las muje- res. Éste es sólo uno de los postulados de su pensamiento-acción para despatriarcalizar la cosmovisión y fundamentos de poder que les limitan como mujeres en sus Comunidades. El territorio, el cuerpo, el espacio, la comunidad, la ancestralidad y otras envolventes, constituyen su análisis para combatirlo, y están presentes en las páginas de dicho capítulo.

Este libro pues, en el que se cartografían las circunstancias y singularidades de la lucha de las mujeres indígenas a lo largo y ancho de Abya Yala, nos da a conocer las ideas de las mujeres indígenas activistas fuera de construcciones y definiciones externas, por lo que su lectura se hace imprescindible para conocer y reconocer la existencia de pensamientos ¿feministas? no hegemónicos, construidos sobre las bases de culturas que comportan definiciones vitales ajenas a la epistemología occidental, construidos por otras propuestas feministas o no calificadas como feministas, para caminar en su Comunidad hacia la Buena Vida, el Buen Vivir o el Vivir Bien, esto es: SUMAK KAWSAY, SUMA QAMAÑA.

\section{Referencias}

Gargallo Celentani, Francesca (2014). Feminismos desde Abya Yala. Ideas y proposiciones de las mujeres de 607 pueblos en Nuestra América. México DF: Corte y Confección.

Martí, José (1980). Nuestra América. Buenos Aires. Editorial Losada, S.A.

\section{Ma ArÁNZAZU RoBles SANTANA}

Licenciada en Historia por la Universidad Complutense de Madrid, Premio Extraordinario en el Máster "Género, Identidad y Ciudadanía" de la Universidad de Cádiz. Actualmente becaria FPI por el Ministerio de Economía y Competitividad del Gobierno de España en el Proyecto I+D (FFI2011-24120) "Justicia, Ciudadanía y Género: Feminización de las Migraciones y Derechos Humanos".

\section{DIRECCIÓN DE CONTACTO}

aranrsantana@gmail.com

\section{FORMATO DE CITACIÓN}

Robles Santana, Ma Aránzazu (2014). Reseña de Gargallo Celentani (2014) Feminismos desde Abya Yala. Quaderns de Psicologia, 16(1), 237-239. http://dx.doi.org/10.5565/rev/qpsicologia. 1200 